\title{
Chinese Harmony Communication Theory: Kompetensi Komunikasi untuk Keseimbangan Hidup
}

\author{
Ira Mirawati, Kismiyati El Karimah \\ Prodi Manajemen Komunikasi Fakultas Ilmu Komunikasi Universitas Padjadjaran
}

\begin{abstract}
ABSTRAK
Chinese Harmony Communication Theory lahir sebagai sebuah wujud usaha aktif untuk mengimbangi teori-teori komunikasi barat, dengan cara mengeksplorasi teori-teori yang berasal dari falsafah hidup orang timur. Salah satu falsafah yang penting untuk digali dalam kaitannya dengan interaksi manusia adalah falsafah orang Cina. Teori yang dikemukakan oleh Guo-Ming Chen pada tahun 2006 ini memperlihatkan bagaimana budaya cina memegang pandangan holistik mengenai komunikasi manusia sebagai sebuat kesatuan besar di mana subjek dan objek secara bersamaan saling melengkapi dan saling padu, lalu manusia cenderung untuk tenggelam dalam kelompok atau secara kolektif berorientasi pada proses interaksi sosial yang tiada akhir. Orang Cina percaya bahwa harmoni tidak hanya panduan untuk mengatur proses komunikasi yang tiada akhir, namun juga tujuan akhir dari komunikasi manusia itu sendiri. Etika komunikasi manusia adalah untuk mencapai kerja sama antar pelaku komunikasi yang berbasis pada ketulusan dan kebersamaan. Dalam interaksi manusia keseharian, orientasi harmoni terihat dari gaya interaksi yang tidak langsung, halus, adaptif atau penuh penyesuaian, konsensual, dan ramah.

Artikel ini menjelaskan Chinese Harmony Communication Theory secara komprehensif dengan menggunakan studi literatur. Di dalamnya dipaparkan sejarah teori, asumsi-asumsi, contoh aplikasi, hingga keterkaitan dengan teori lain.
\end{abstract}

Kata-kata Kunci: Chinese Harmony, Yin Yang, Guo-Ming Chen, Etika Komunikasi

\section{Chinese Harmony Communication Theory: Communication Competence for Life Balance}

\begin{abstract}
Chinese Harmony Communication Theory is an active effort to balance the theories of western communication, by exploring theories derived from the eastern philosophy of life. One of the important philosophies to be explored in relation to human interaction is Chinese philosophy. The theory put forward by Guo-Ming Chen in 2006 shows how Chinese culture holds a holistic view of human communication as a large entity in which subjects and objects simultaneously complement and co-exist, then humans tend to be immersed in groups or collectively oriented in the process of endless social interaction. The Chinese believe that harmony is not only a guide to regulating an endless communication process, but also the ultimate goal of human communication itself. The ethics of human communication is to achieve cooperation between communication actors based on sincerity and togetherness. In everyday human interaction, harmony orientation is seen from the style of interaction that is indirect, subtle, adaptive or full of adjustment, consensual, and friendly.

This article describes the Chinese Harmony Communication Theory comprehensively using literature studies. It explained the history of theory, assumptions, examples of applications, and the relevance with other theories.
\end{abstract}

Keywords: Chinese Harmony, Yin Yang, Guo-Ming Chen, Communication Ethics

Korespondensi: Dr. Ira Mirawati, M.Si. Universitas Padjadjaran. Jln. Raya Bandung-Sumedang Km.21 Jatinangor. Email: ira.mirawati@unpad.ac.id

ISSN: 2548-3242 (cetak), eISSN: 2549-0079 Website: http://jurnal.unpad.ac.id/manajemen-komunikasi 


\section{PENDAHULUAN}

Adalah Guo-Ming Chen, Profesor ilmu komunikasi University of Rhode Island (URI) yang mengemukakan Chinese Communication Theory. Ia merupakan penerima Outstanding dissertation Award dari Divisi International dan Intercultural Communication NCA (National Communication Association).

Kepeduliannya Chen terhadap perkembangan ilmu komunikasi di dunia timur berjalan seiring dengan jabatannya sebagai ketua Eastern Communication Association (ECA), dan direktur eksekutif Internasional Association for Intercultural Communication Studies. Banyak sekali karya yang telah dihasilkan oleh Guo Ming Chen, diantaranya adalah Editor Buku Intercultural Communication Studies, China Media Research, International and Intercultural Communication Annual, Foundations of Intercultural Communication, Communication and Global Society, Dialogue among Diversities, Chinese Conflict Management and Resolution, Introduction to Intercultural Communication, Theories and Principles of Chinese Communication, An Introduction to Media Literacy, Chinese Perspective of Conflict Management and Resolution, Asian Perspective of Culture and communication, Communication Research Methods, Communication Theories.
Ketertarikan utama Chen di bidang intercultural organizational global communication sangat dikenal seiring dengan publikasinya di berbagai jurnal/artikel/chapter buku, yang saat ini melebihi 150 artikel, di antaranya dimuat di Communication Quarterly, Communication Yearbook, Journal of Asian Communication, Journal of Cross-Cultural Psychology, China Media Research, Death Studies, Human Communication, Communication Research Reports, Intercultural Communication Studies, The Howard Journal of Communications, dan Journal of Psychology.

Bila dilihat dari pemaparan Guo Ming chen dalam artikelnya yang berjudul "Towards Transcultural Communication: A Harmony Theory of Chinese Communication" (China Media Research, 2008) dan “An Introduction to Key Concepts of Understanding Chinese: Harmony as The Foundation of Chinese Communication" (China Media Research, 2011), teori ini lahir sebagai sebuah wujud usaha aktif untuk mengimbangi teori-teori komunikasi barat, dengan cara mengeksplorasi teori-teori yang berasal dari falsafah hidup orang timur. Salah satu falsafah yang penting untuk digali dalam kaitannya dengan interaksi manusia adalah falsafah orang Cina. Mengapa demikian? 
Ada dua kondisi yang "memaksa" untuk memahami perilaku komunikasi orang Cina, yakni:

1) Dalam beberapa dekade terakhir, Cina merupakan negara dengan penduduk terbesar dan memiliki pertumbuhan ekonomi yang pesat. Orang-orang Cina di berbagai belahan dunia, terutama Hong Kong, Macao, Cina daratan, dan Taiwan memiliki jaringan kuat yang mempengaruhi berbagai aspek ekonomi dunia.

2) Dunia terus bergerak ke arah komunitas global, pemahaman bersama di antara manusia dari berbagai latar belakang budaya menjadi kebutuhan yang tidak terelakkan untuk dapat hidup bersama secara efektif dan produktif.

Kedua poin di atas menunjukkan pada bahwa tidak berlebihan rasanya jika dikatakan bahwa memahami komunikasi Cina adalalah kunci untuk kesuksesan menghadapi globalisasi. Dengan memahami cara berpikir dan bertindak orang Cina akan menjadi sebuah langkah awal menciptakan dunia yang damai dan saling berhubungan. Bukan tidak mungkin, kurangnya kesadaran kultural ketika berkomunikasi (khususnya dengan orang Cina) akan menghasilkan ekspektasi yang tidak realistik, rasa frustasi, dan kegagalan menghadirkan hubungan interkultural.
Ada tiga hal utama yang menjadi perhatian utama dalam pengkajian perilaku komunikasi orang Cina, yakni:

1. Tren penelitian-penelitian komunikasi pribumi (indigenous),

2. Harmoni sebagai landasan asumsi paradigmatik dari komunikasi Cina,

3. Kesulitan penelitian-penelitian komunikasi Cina.

Salah satu tren yang paling menonjol dalam perkembagan penelitian akademik yang terdorong oleh adanya globalisasi di akhir tahun 1990an adalah tantangan bagi para ilmuwan, terutama dari dunia nonBarat, untuk mengkaji ulang dominasi eurosentrisme dengan mempertanyakan kesesuaian paradigma eurosentris yang selama ini digunakan untuk mengkaji masyarakat-masyarakat di berbagai penjuru dunia. Untuk mengimbangi dominasi barat ini dengan perspektif kontinental, seperti afrosentrisme atau asiasentrisme, maka semakin banyak ilmuwan yang melakukan pendekatan emik untuk meneliti budayabudaya atau area spesifik di benua mereka. Contohnya, konsep amae (kebutuhan perluasan dan penerimaan pesan), enryosasshi (pengendalian-penaksiran), dan en (takdir sebuah hubungan) dalam komunikasi Jepang. Di korea ada uye-ri (saling melengkapi dan memerlukan), di Filipina ada Kapwa (prinsip saling membalas), pahiwatig (kedwimaknaan strategis), dan pakiramdam (kapasitas untuk merasakan 
perasaan orang lain). Sementara itu, di Thailand ada kreng jai (menjalin tenggang rasa dengan erat).

Asante (2006) menyatakan bahwa dominasi eurosentrisme disebabkan oleh sikap triumphalisme barat. Triumphalisme adalah kegembiraan yang berlebihan karena pencapaian atau prestasi seseorang, yang diilustrasikan melalui individualisme agresif, rasionalisme chauvinistic (perasaan atau perilaku patriotisme/fanatikal yang berlebihan), dan kulturalisme yang kejam dan pda akhirnya mengarahkan para peneliti non-barat untuk ikut menggunakan pandangan mereka dengan pembenaran globalisasi. Chen merangkum tiga aspek triumphalisme yang diindikasikan oleh Asante, sebagai berikut:

1) Individualisme agresif ditempelkan pada paradigm eurosentris yang dicirikan dengan kemandirian, otonomi, kebebasan, dan kemerdekaan individu. Empat hal ini cenderung menghambat gagasan-gagasan tentang kerja sama manusia.

2) Rasionalisme chauvinistik mengasumsikan bahwa hanya orang eropa yang memili hak untuk mendefinisikan apa dan bagaimana cara mendekati reallita.

3) Ruthless culturalism (kulturalisme kejam) mempromosikan ide-ide orang Eropa dan Amerika sebagai kelompok manusia yang paling benar.
Menurut Chen, dominasi eurosentrisme ini pada akhirnya akan mengarah pada marjinalisasi, penindasan, fitnah, dan ekslusifitas terhadap paradigmaparadigma yang datang dari ilmuwan noneropa. Oleh karena itu, untuk mengatasi permasalahan ini, pendekatan budaya spesifik harus dibangun dalam mempelajari perilaku manusia. Chen dan para Ilmuwan Cina lainnya sepakat bahwa dari fase kritik ini mereka harus bergerak kearah pembangunan teori.

Tren untuk mengangkat nilai-nilai komunikasi budaya cina sejak awal tahun 1990 mencerminkan gerakan deWesternisasi dan dapat dianggap sebagai bagian dari usaha untuk membangun paradigma komunikasi asiasentris. Menurut Chen, ini adalah waktu yang tepat bagi perspektif budaya cina untuk membangun teori-teori sosial agar dapat berkompetisi dengan paradigma lain, dibandingkan hanya sekadar melanjurkan kritik terhadap eurosentrisme dan westernisasi.

\section{METODE PENELITIAN}

Artikel ini ditulis dengan menggunakan metode studi literatur. Sumber utama adalah artikel-artikel ilmiah Chen, yakni: 1) Chen, Guo Ming, William J. Starosta, 1997, Chinese Conflict Management and Resolution: Overview and Implication", Journal of Intercultural Communication Studies VII: 1 1997-8; 2) 
Chen, Guo Ming, An Introduction to Key Concepts in Understanding the Chinese: Harmony as the Foundation of Chinese Communication, China Media Research, 7(4), 2011; 3) Chen, Guo-Ming, 2009, Toward an I Ching Model of Communication, China Media Research, 5(3); 4) Chen, Guo Ming, 2008, Towards Transcultural Understanding: A Harmony Theory of Chinese Communication, China Media Research, 4(4), 2008.

\section{HASIL DAN PEMBAHASAN}

\section{Tradisi dan Paradigma Teori}

Meskipun teori ini beradal dari Timur, Littlejohn dan Foss dalam buku Encyclopedia of Communication Theory (ebook version, 2009) menyatakan bahwa teori ini sangat dapat digolongkan ke dalam tujuh tradisi komunikasi, karena meskipun didesain untuk mengorganisasikan teori-teori barat, tujuh tradisi ini juga dapat digunakan untuk mendiskusikan berbagai teori timur.

Selanjutnya, Littlejohn dan Foss menerangkan bahwa teori-teori asia banyak yang kongruen dengan pendekatan sistem pada tradisi sibernetik. Alasannya: baik teoriteori sistem maupun filosofi asia menekankan pada keseluruhan, selain itu keduanya memiliki fenomena ontologi yang memandang bagian-bagian sebagai sesuatu yang saling berhubungan dan saling bergantung. Bukan hanya itu, keduanya juga menganggap bahwa arah waktu bukan searah dan berhenti di satu titik melainkan terus berlangsung tanpa akhir.

Littlejohn dan Foss secara gamblang menyebutkan bahwa teori-teori Cina dengan paradigm yijing temasuk dalam tradisi ini. Paradigma yijing adalah paradigma harmoni itu sendiri. Chung Ying Cheng (Profesor Departemen Filsafat, University of Hawaii) dalam artikelnya "On Harmony as Transformation: Paradigm from The Yijing" (Jurnal of Chinese Philosophy, 2009), menyebutkan bahwa harmoni bermakna saling menyempurnakan antarbagian dan saling melengkapi di antara anggota masyarakat, yang akan menghasilkan totalitas kesempurnaan.

Chen dengan gamblang menyebutkan bahwa harmoni merupakan paradigma dari teori yang dibangunnya. Paradigma adalah asumsi filosofis atau "worldview" dari kelompok manusia. Paradigma akan membimbing cara berpikir, kepercayaan, tindakan anggota kelompok pada jalan tertentu.

Chen menyebutkan empat elemen paradigma teori komunikasi yang dibangunnya mencakup ontologi, aksiologi, epistemologi, dan metodologi. Ontologi merupakan nature atau kealamiahan komunikasi manusia, aksiologi berkaitan dengan tujuan utama komunikasi manusia, epistemologi berkenaan dengan cara untuk mendapatkan pengetahuan tentang komunikasi manusia, dan metodologi 
berkenaan dengan cara mencapai tujuan komunikasi manusia.

Pada model yang dibuat oleh Chen pada tahun 2006 (diadaptasi oleh penulis ke dalam gambar 1), terlihat bahwa budaya cina memegang pandangan holistic mengenai komunikasi manusia sebagai sebuat kesatuan besar di mana subjek dan objek secara bersamaan saling melengkapi dan saling padu, lalu manusia cenderung untuk tenggelam dalam kelompok atau secara kolektif berorientasi pada proses interaksi social yang tiada akhir. mengatur proses komunikasi yang tiada akhir, namun juga tujuan akhir dari komunikasi manusia itu sendiri. Etika komunikasi manusia adalah untuk mencapai kerja sama antar pelaku komunikasi yang berbasis pada ketulusan dan kebersamaan. Dalam interaksi manusia keseharian, orientasi harmoni terihat dari gaya interaksi yang tidak langsung, halus, adaptif atau penuh penyesuaian, konsensual, dan ramah.

Secara epistemologi, orang Cina percaya hampir semua hal dalam hidup manusia hanya berarti dan dapat dipersepsi dalam hubungannya dengan orang lain.

\begin{tabular}{|c|c|c|}
\hline & $\begin{array}{c}\text { ONTOLOGI } \\
\text { (hakikat komunikasi manusia) }\end{array}$ & \\
\hline & Menyeluruh (holistic) & \\
\hline & $\begin{array}{l}\text { Tenggelam dalam kelompok } \\
\text { Kolektivis }\end{array}$ & \\
\hline $\begin{array}{l}\text { AKSIOLOGI } \\
\text { (Tujuan Akhir) }\end{array}$ & $\begin{array}{l}\text { EPISTEMOLOGI } \\
\text { (Cara Mengetahui) }\end{array}$ & $\begin{array}{l}\text { METODOLOGI } \\
\text { (Cara Mencapai }\end{array}$ \\
\hline Harmonisasi & Saling berhubungan & intuitif \\
\hline $\begin{array}{l}\text { tidak langsung } \\
\text { halus } \\
\text { adaptative } \\
\text { konsensual } \\
\text { ramah }\end{array}$ & $\begin{array}{c}\text { Saling balas } \\
\text { kami } \\
\text { hirarkis } \\
\text { asosiatif } \\
\text { menelisik asal muasal }\end{array}$ & $\begin{array}{l}\text { subyektif } \\
\text { nonlinear } \\
\text { dwimakna } \\
\text { ritual } \\
\text { akomodatif }\end{array}$ \\
\hline
\end{tabular}

Maka, kesalingte rhubunga n antara yang mengetah ui (knower) dan yang diketahui (known) adalah

Gambar 1. Empat elemen paradigma Teori Komunikasi Harmoni menurut Chen Sumber: Chen, Guo Ming, An Introduction to Key Concepts in Understanding the Chinese: Harmony as the Foundation of Chinese Communication, China Media Research, 7(4), 2011

Secara aksiologi, orang Cina percaya bahwa harmoni tidak hanya panduan untuk inti dari pengetahuan yang asli. Realitas nondualistik dari hubungan sesama tercermin dalam penekanan hubungan manusia yang saling balas, perasaan sebagai-kita, hirarkikal, asosiatif, dan melihat asal muasal.

Terakhir, asumsi metodologikal dari komunikasi manusia dalam budaya cina mensyaratkan siklus berpikir nonlinear, yang 
berarti sebuah metode dimana suatu tujuan yang sama dapat dicapai melalui berbagai jalur, dan jalur tersebut terletak pada sebuah jaring definisi bersama atau hubungan yang saling melengkapi. Siklus nonlinear ini cenderung subjektif, nonlinear, mengandung banyak makna, memandang penting ritual dan memiliki pola akomodatif.

Meskipun pandangan ontologikal memperlihatkan orientasi aksiologis, epistemologis, dan metodologis dari paradigm berpikir kelompok, tujuan akhir dari asumsi aksiologi sebuah interaksi adalah aspek yang paling membuktikan ketika kita menguji komunikasi manusia. Pandangan Chen ini selaras dengan pandangan Catherine Miller yang mengatakan bahwa saat ini, aksiologis adalah hal yang paling penting untuk memberi arah penelitian komunikasi (2002:31).

\section{Proposisi, Aksioma, dan Teorema yang Dibangun}

Berdasarkan konsep keseimbangan Cina, pada tahun 2001 Guo Ming Chen kemudian mengembangkan teori harmoni komunikasi Cina (Harmony Theory of Chinese Communication). Teori yang telah diaplikasikan dalam berbagai perilaku komunikasi, terutama dalam manajemen konflik di Cina ini terdiri dari empat proposisi, 23 aksiona, dan 23 teorema.

Proposisi ialah kalimat logika yang merupakan pernyataan tentang hubungan antara dua atau beberapa hal yang dapat dinilai benar atau salah. Dengan kata lain, Proposisi sebagai pernyataan yang didalamnya manusia mengakui atau mengingkari sesuatu tentang sesuatu yang lain. Aksioma adalah semacam dalil yang kebenarannya tidak perlu dibuktikan namum akan dijadikan dasar untuk membuktikan dalil atau teorema selanjutnya. Sementara Teorema adalah suatu pernyataan matematika yang masih memerlukan pembuktian dan pernyataanya dapat ditunjukkan nilai kebenarannya atau bernilai benar (Jacobs, 1982).

Teori ini menyatakan bahwa kemampuan untuk meraih kondisi harmoni dalam hubungan manusia adalah kriteria utama untuk mengevaluasi kompetensi komunikasi seseorang. Dengan kata lain, semakin tinggi kemampuan seseorang mencapai harmoni maka semakin tinggi pula derajat kompetensi komunikasinya.

Ada tiga prinsip yang harus diikuti untuk mencapai harmoni:

1. Internalisasi nilai-nilai intrinsic (intrinsically internalize), mencakup jen (humanisme), $\quad y i$ (kebajikan), dan $l i$ (tata cara);

2. Mengakomodari kondisi ekstrinsik (extrinsically accommodate), mencakup shi (Kemungkinan temporal), wei (kemungkinan ruang), dan $j i$ (gerakan permulaan yang tak terlihat); 
3. Latihan secara strategis (strategically exercise), mencakup Cina.

quanxi (interrelation), mientz(face), dan and power (kekuatan) in the behavioral level.

\section{Jen, $\mathrm{Yi}$, and $\mathrm{Li}$}

Pada Jen, terdapat prinsip reciprocity (timbal balik) dan empati. Jen merupakan kebajikan kolektif yang menunjukkan cinta dalam interaksi. Melalui proses bebas yang secara empati dan bersama, esensi dari Jen dipancarkan untuk membangun interaksi secara harmonis.

$Y i$ adalah kriteria internal dari perilaku komunikasi yang menjadikan individu memiliki kapasitas untuk menunjukkan kemampuan adaptasi dan fleksibel dalam konteks spesifik yang diatur oleh norma untuk mencapai harmoni.

$\mathrm{Li}$ menggambarkan formalitas dari interaksi manusia dan menghubungkan karakter dan tugas social individu dengan mengikuti aturan-aturan dari tingkah laku dan bicara dalam komunikasi. Hanya dengan mengikuti $l i$, individu dapat secara aktif menyesuaikan diri pada keharmonian dan struktur hirarki masyarakat, menghindar dari konfrontasi memalukan, dan mengatasi situasi sosial yang ambigu untuk menegakkan kontrol kelompok terhadap kecenderungan egosentris.

Tiga konsep intrinsik ini membentuk dasar dari struktur dalam dari interaktan dalam menciptakan keharmonian komunikasi

Shi, Wei, Ji

Shi membutuhkan kemampuan mengetahui hubungan temporal untuk menampilkan secara tepat perilaku yang seharusnya dilakukan dalam tahapan-tahapan yang berbeda dari interaksi manusia. Ketidakmampuan untuk mengenali perubahan kemungkinan konteks waktu dalam interaksi adalah hal yang dapat mengganggu tercapainya harmoni dan akan menyebabkan kegagalan komunikasi.

Wei merupakan kontigensi spasial yang terdiri dari konteks sosial dan lingkungan komunikasi. Dengan menguasai wei berarti seseorang dapat menyadari dan membedakan who, what, dan where dari proses interaksi, yang merefleksikan struktur hirarki hubungan manusia.

$J i$ adalah tanda-tanda tersembunyi dari sebuah perilaku yang sebenarnya menunjukkan alternative atau konsekuensikonsekuensi yang mungkin dalam interaksi yang sedang berjalan. Orang yang kompeten menurut Cina adalah yang mampu mengembangkan kondisi keharmonisan dengan mengetahui apa yang tersembunyi dan apa yang tampak selama interaksi. Untuk itu diperlukan sensitifitas dan ketulusan.

Bila diletakkan dalam sebuah diagram, elemen intrinsik (Jen, yi, li) adalah latitude dan elemen ekstrinsik (shi,wei,ji) adalah 
longitude. Bersama mereka mendinamiskan konteks-konteks komunikasi cina.

\section{Guanxi, Mientz, and Power}

Guanxi (bisa dibaca quanxi) merupakan keterikatan particular dari para interaktan dalam struktur hirarki jaringan sosial cina. Jaringan ini merupakan sumber social orang cina untuk dapat mempersuasi, mempengaruhi, dan mengontrol interaksi dalam mencapai harmoni atau kompetensi. Kemampuan untuk membedakan level-level dari hubungan hierarkikal dalan interaksi social berfungsi untuk mengembangkan iklim komunikasi yang suportif dan harmoni.

Dalam komunikasi bisnis, guanxi dapat didefinisikan lebih spesifik sebagai jaringan atau hubungan timbal balik yang saling menguntungkan antara dua pihak. Hanya saja, hubungan yang terjalin ini berada di luar konteks formal. Di Tiongkok, kesepakatan-kesepakatan penting dalam bisnis kerap terjadi dalam pertemuan santai antarentrepreneur yang tengah bersantap malam atau menikmati sajian minuman beralkohol di waktu senggang mereka. Karena itulah, bila seseorang memiliki hubungan yang baik dengan orang lain di luar pekerjaan, biasanya karir dan bisnisnya akan lebih lancar daripada mereka yang berusaha membatasi kehidupan sosialnya untuk menjaga privasi, sesuatu yang biasa dilakukan oleh para pebisnis Barat.
Mientz adalah kepercayaan diri atau prestise social yang diperolah dari rasa hormat lawan bicara. Orang cina yang kompeten adalah yang selalu mengetahui bagaimana menyenangkan orang dan menghindari ketidaknyamanan emosi orang lain.

Power dalam masyarakat Cina ditempelkan pada strukur hierarki dalam jaringan social yang memunculkan kekuatan berupa senioritas untuk memegang dan menguasai. Semakin tua dan tinggi status sosial seseorang adalah lokus dari power, tidak hanya dalam interaksi personal dan sosial, namun juga dalam dunia kerja.

Fungsi-fungsi dan hubungan dari konsep-konsep itu membentuk sistem holistic dari komunikasi orang cina yang ideal. Interaksi dan integrasi dari Sembilan elemen itu yang akan membawa pada proses transformasi berkelanjutan dari komunikasi orang cina. Jadi bagi orang cina, harmoni adalah kondisi equilibrium yang merepresentasikan pemenuhan komunikasi kompeten yang ditunjukkan dengan tercapainya tujuan komunikasi manusia, yaitu:

1. Perasaan aman

2. Perasaan kebersamaan,

3. Perasaan bahagia berinteraksi

4. Perasaan beruntung karena berinteraksi 
Meskipun dalam teori ini Chen Teorema 1

mengembangkan aksioma dan teorema Semakin seseorang mampu memberikan dengan rumus-rumus semakin $\mathrm{X}$ akan timbal balik, semakin kompeten orang semakin $\mathrm{Y}$, namun sifatnya adalah tersebut dalam komunikasi.

probabilitas atau kemungkinan- Teorema 2

kemungkinan.

Semakin empatik seseorang, maka akan

Aksioma-aksioma dan teorema- semakin kompeten orang tersebut dalam teorema ini juga dibangun untuk komunikasi

mengembangkan teori ini menjadi sebuah teori yang bukan hanya menggali falsafah YI

namun menyediakan pedoman untuk Aksioma 4

meningkatkan kompetensi komunikasi Cina. semakin tinggi derajat $y i$, semakin besar kemungkinan terbangunnya harmoni dalam

\section{Aksioma dan Teorema}

Aksioma 1 atau aksioma utama dari teori ini adalah:

"Semakin meningkat kemampuan untuk mencapai harmoni, akan meningkatkan derajat kompetensi komunikasi”.

\section{JEN}

Aksioma 2

"semakin tinggi tingkat jen, semakin tinggi kemungkinan berkembangnya harmoni pada komunikasi”

\section{Aksioma 3}

Semakin tinggi derajat humanisme seseorang, semakin tinggi kemungkinan bahwa Jen akan terjaga dalam komunikasi Cina.

\section{komunikasi.}

\section{Aksioma 5}

Semakin tinggi derajat kepatutan, semakin tinggi kemungkinan terjaganya $y i$ dalam komunikasi.

\section{Teorema 3}

Semakin fleksibel seseorang, akan semakin kompeten orang tersebut dalam komunikasi.

\section{Teorema 4}

Semakin seseorang mampu beradaptasi, akan semakin kompeten orang tersebut dalam komunikasi Cina.

\section{LI}

\section{Aksioma 6}

peningkatan praktik $l i$ akan menghasilkan peningkatan terbangunnya harmoni dalam komunikasi.

Aksioma 7 
Semakin terampil seseorang dalam WEI

mengelola bahasa kehormatan, semakin Aksioma 10

kompeten orang tersebut dalam komunikasi. Meningkatnya pengetahuan tentang wei akan

Teorema 6 mengingkatkan pembangunan harmony

Semakin terampil seseorang dalam dalam komunikasi.

berususan dengan hirarki hubungan social, Aksioma 11

akan semakin kompeten orang tersebut Semakin tinggi derajat pengetahuan dalam komunikasi.

Teorema 7

kemungkinan spasial, semakin tinggi kemungkinan wei akan dapat dijaga dalam

Semakin sopan seseorang, akan semakin komunikasi.

kompeten orang tersebut dalam komunikasi. Teorema 11

Teorema 8

Semakin seseorang mengetahui lingkungan

Semakin terampil seseorang dalam komunikasinya, akan semakin kompeten mengontrol emosi, akan semakin kompeten seseorang dalam komunikasi. seseorang dalam komunikasi.

Teorema 12

Teorema 9

Semakin sedikit sifat agresif seseorang, akan

Semakin seseorang mengetahui konteks sosial, akan semakin kompeten seseorang semakin kompeten orang tersebut dalam dalam komunikasi.

komunikasi Cina.

\section{SHI}

Aksioma 8

Semakin meningkat pengetahuan tentang shi akan meningkatkan perkembangan harmoni dalam komunikasi.

Aksioma 9

Semakin tinggi derajat pengetahuan kemungkinan temporal, semakin tinggi kemungkinan akan terjaganya shi.

Teorema 10

Semakin seseorang mengetahui kapan Teorema 13

waktunya untuk bertindak yang sesuai, Semakin

semakin kompeten seseorang dalam kemungkinan konsekuensi-konsekuensi dari komunikasi.

Aksioma 12

Meningkatnya pengetahuan tentang $j i$ akan meningkatkan pembangunan harmoni dalam komunikasi.

aksioma 13

Semakin tinggi derajat dalam mengetahui kemungkinan konsekuensi-konsekuensi dari sebuah interaksi, semakin tinggi kemungkinan bahwa $j i$ dapat dijaga dalam komunikasi.

seseorang mengetahui

$J I$ 
sebuah interaksi, semakin seseorang akan kompeten dalam komunikasi.

MIENTZ

Teorema 14

Aksioma 16

Ssemakin sensitif sesesorang, semakin ia Penguatan Mienz akan menghasilkan akan kompeten dalam komunikasi.

penguatan pembangunan quanxi dalam Teorema 15 komunikasi.

Semakin tulus seseorang, ia akan semakin Aksioma 17 kompeten dalam komunikasi.

Penguatan mientz akan menghasilkan penguatan dalam membangun harmony

GUANXI komunikasi.

\section{Aksioma 14}

Aksioma 18

Semakin kuat guanxi, akan semakin kuat juga pembangunan harmoni dalam komunikasi.

\section{Aksioma 15}

Semakin tinggi derajat menghormati orang

Semakin tinggi derajat dalam mendirikan lain, semakin tinggi kemungkinan bahwa mientz akan terpelihara dalam komunikasi.

\section{Aksioma 19}

hubungan-hubungan tertentu, semakin tinggi kemungkinan bahwa guanxi akan dapat dipelihara dalam komunikasi.

Teorema 16

Semakin tinggi derajat renqin terhadap orang lain, semakin tinggi kemungkinan bahwa mientz akan dapat dipelihara dalam komunikasi.

\section{Teorema 19}

Semakin seseorang mengetahui bagaimana Semakin seseorang mengetahui bagaimana membangun hubungan dengan orang-orang, meningkatkan mientz orang lain, akan akan semakin kompeten ia dalam komunikasi.

semakin kompeten ia dalam komunikasi.

Teorema 20

Teorema 17

Semakin terampil seseorang dalam Semakin terampil seseorang dalam melakukan hal-hal yang untuk membedakan anggota kelompok dari orang di luar kelompok, akan semakin kompeten orang tersebut dalam komunikasi.

menyenangkan orang lain, akan semakin kompeten ia dalam komunikasi.

Teorema 21

Teorema 18

Semakin kuat perasaan "berhutang" yang

Semakin kuat "we feeling" (perasaan ke dimiliki seseorang, akan semakin kompeten kitaan) yang dimiliki seseorang, akan ia dalam komunikasi. semakin kompeten orang tersebut dalam komunikasi. 


\section{POWER}

Aksioma 20

Pengerahan kekuatan yang sesuai akan menghasilkan penguatan dalam membangun harmoni dalam komunikasi.

Aksioma 21

Peningkatan guanxi akan meningkatkan pembangunan kekuatan dalam komunikasi.

Aksioma 22

Semakin tinggi derajat senioritas, akan menghasilkan peningkatan dalam membangun kekuatan dalam komunikasi.

Aksioma 23

Peningkatan derajat atoritas akan menghasilkan peningkatan pembangunan kekuatan dalam komunikasi.

Teorema 22

Semakin senior seseorang, akan semakin dipersepsi kompeten dalam komunikasi.

Teorema 23

Semakin seseorang memiliki otoritas, akan semakin dipersepsi kompeten seseorang dalam komunikasi.

\section{Model I Ching}

Bukan hanya membangun aksioma dan teorema, Chen juga mengembangkan sebuah model untuk menggambarkan bagaimana harmonisasi komunikasi tercapai dengan yin yang sebagai sumbunya. Model tersebut ia namakan dengan model komunikasi I Ching.

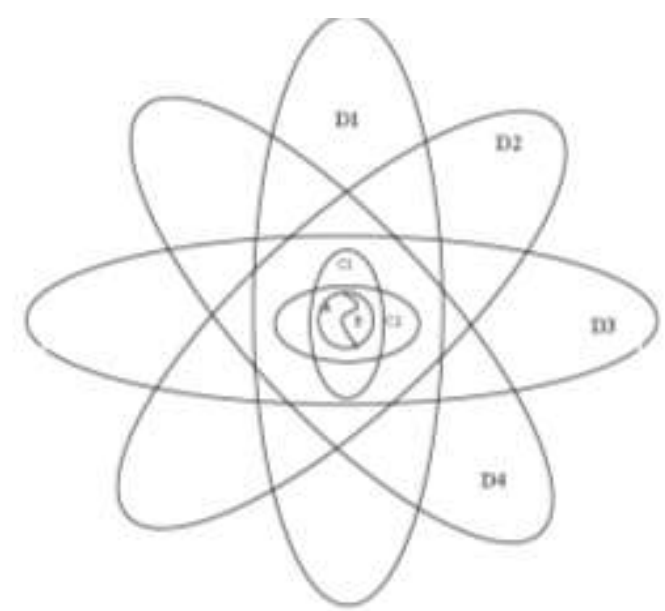

Gambar 2. Model Komunikasi I Ching Sumber: Chen, 2009

I Ching (biasa juga dibaca I tsing, juga dikenal dengan yi jing) sebenarnya adalah sebuah model dalam menyikapi berbagai hal di dunia ini dengan berpusat pada keseimbangan antara yin dan yang. Model memaknai kehidupan dan cara bertindak dalam berbagai aspek kehidupan ini sudah berkembang di Cina sejak tahun 221 SM (Dinasti Zhou)

Pandangan dari interaksi antara yin dan yang sebagai sumber kehidupan menjadi kerangka yang digunakan orang Cina untuk menjelaskan naik turunnya, perkembangan dan penurunan aktivitas manusia (Xiao, 2006). Lebih dari itu, keadaan dinamis namun seimbang untuk interaksi dan transformasi yin dan yang adalah kunci untuk mempertahankan hidup. Kurangnya harmoni menunjukkan tidak adanya keseimbangan dinamis, yang menghasilkan kegagalan tindakan manusia. 
Pada model Komunikasi I Ching yang berbentuk hexagram tersebut, garis yang ada di atas disebut dengan "driving line" dan yang berada dibawah disebut dengan "receptive line". Driving line merupakan representasi dari yang atau kekuatan dominan, sementara receptive line melambangkan yin atau kekuatan yang tunduk pada atau menerima yang. Adalah tidak baik jika garis yin berada di atas garis yang.

Menurut I Ching model of communication, stabilitas hubungan hirarkis berdasarkan pada interaksi dinamis antara enam garis ditentukan oleh tiga unsur berakar pada heksagram: shi (temporal contingencies), wei (spasial contingencies), dan ji (gerakan yang tak terlihat dari sebuah perilaku).

Dengan kata lain, jaringan hirarkis yang harmonis dari sebuah hubungan adalah fungsi dari pengenalan jejak perubahan (yaitu ji) dan mengetahui waktu yang tepat (yaitu shi) untuk berperilaku tepat dalam konteks tertentu dengan tepat atribut (yaitu wei). Lima karakteristik komunikasi manusia yang digambarkan oleh model i ching adalah: holistik, hirarkis, saling berhubungan, kreatif, dan harmonis. Pertama, komunikasi manusia adalah sistem holistik. Sistem holistik dibentuk oleh kedinamisan, interaksi dialektis antara yin dan yang (diwakili oleh B dan A dalam model). Meskipun yin (dan yang) sendiri adalah suatu sistem di mana kekuatan sendiri menghasilkan proses transformasi internal, namun menurut I Ching, yin yang saja tidak akan menghasilkan dan mengembangkan komunikasi yang harmonis.

\section{Contoh Kasus}

Teori ini dapat diterapkan untuk mengatasi konflik, terutama guanxi (interrelation) dan mientz (face) dalam kaitannya untuk mencapai harmoni. Dalam sebuah artikel berjudul "Chinese Conflict Management and Resolution: Overview and Implication" Guo Ming chen dan William J. Starosta menuliskan beberapa penelitian tentang cara-cara orang Cina dalam mengelola konflik. Penelitian tersebut diantaranya: "Guanxi dan Mientze: Conflict Resolution in China Society, "Kwang-Kuo Hwang menyediakan model teoritis untuk menjelaskan cara Cina memanajemen konflik. Menggunakan konsep "keharmonisan" sebagai sumbu dan guanxi (interrelasi) dan mientze (wajah) sebagai dua sayap harmoni, model ini diterapkan untuk tiga kategori jaringan antarpribadi Cina: vertikal dalam kelompok, horisontal dalam kelompok, dan horisontal di luar kelompok. Ada lima gaya resolusi konflik untuk mencapai keharmonian yakni: konfrontasi, pemutusan, kesabaran, mematuhi publik / menentang pribadi, dan kompromi.

Komunikasi harmoni juga diterapkan dalam komunikasi keluarga, seperti ulasan 
Chen dan Starosta tentang upaya membandingkan negosiasi yang terjadi penyelesaian konflik dengan perspektif antara pengasuh Cina dan balita mereka saat Harmoni dalam penelitian Yanru Chen dan konflik, dengan negosiasi di negara barat Xiaoming Hao yang berjudul: "Resolusi khususnya Inggris dan Amerika Serikat. Konflik Cinta Segitiga: Perspektif yang Analisis menunjukkan bahwa orang dewasa Ditawarkan oleh Drama TV Cina". Chen dan Cina, berbeda dengan orang dewasa Inggris Hao menganalisis 300 episode 15 drama TV Cina 1992-1995 yang melibatkan hubungan cinta segitiga. Mereka melaporkan tujuh penyebab utama konflik di segitiga pecinta China yang digambarkan dalam drama TV: (1) konflik antara mengejar pengetahuan dan uang, (2) konflik antara aspirasi karir dan peran dalam keluarga, (3) konflik yang timbul dari perjodohan,(4) konflik akibat tujuan hidup yang berbeda, (5) konflik yang disebabkan oleh perubahan status sosial, (6) konflik disebabkan oleh pernikahan tanpa cinta, dan (7) konflik yang disebabkan oleh kurangnya kasih sayang. Para peneliti menemukan bahwa gaya mengelola dan menyelesaikan konflik cinta segitiga cenderung nonkonfrontatif. untuk mencapai resolusi banyak cara yang mereka lakukan, mulai dari intervensi orang tua, atau bantuan organisasi, yang tujuan akhirnya adalah rekonsiliasi.

Di Cina, komunikasi harmoni ternyata bukan hanya diterapkan pada orang dewasa, namun sudah diajarkan sejak dini pada anakanak. Chen mencontohkannya melalui penelitian Twila Tardif yang berjudul "Negosiasi dalam Konflik antara Pengasuh dan AS, lebih sering menggunakan kegiatan alternatif dan menggunakan strategi lain dalam bernegosiasi dengan balita daripada langsung mengeluarkan penolakan/ penentangan eksplisit. Sejalan dengan itu anak-anak Cina cenderung menggunakan strategi tidak menanggapi atau mengabaikan permintaan para pengasuh daripada langsung menolak atau tidak mematuhi. Tindakantindakan ini dilakukan agar konflik dapat teredam dan keharmonisan tidak rusak.

Untuk orang Cina, konflik tidak dianggap sebagai masalah komunikasi melainkan sebagai pengganggu harmoni. Komunikasi manusia adalah bukan proses di mana manusia berusaha untuk mengarahkan interaksi untuk kebaikan kita sendiri. Sebaliknya, itu adalah suatu proses dinamis untuk beradaptasi, saling ketergantungan, dan bekerja sama. setiap orang ulus menampilkan perhatian sepenuh hati untuk orang lain karena itu adalah pintu gerbang ke mencapai hubungan yang harmonis. Akibatnya, tujuan interaksi Cina adalah membangun hubungan interpersonal dan sosial yang bebas konflik (Chen \& Chung, 1994) dan Balita di Beijing". Tardif 
Kekuatan dan Kelemahan Teori

Teori harmoni komunikasi Cina ini secara simultan menyediakan solusi dan norma untuk mengatasi permasalahan komunikasi dan kemanusiaan. Metodologi yang ditawarkannya merupakan sudut pandang baru dalam melihat permasalahan komunikasi manusia yang berbeda dengan bagaimana dunia barat melihatnya. Dengan teori ini, permasalahan-permasalahan tersebut dipahami dari sisi filosofis, yang akan membawa pada pencerahan individu, "kesolehan" social, dan harmonisasi politik. Secara bersamaan, substansi dan metodologi yang ditawarkan filosofi Cina menyediakan kerangka kerja komprehensif untuk merencanakan dan mengevaluasi ulang permasalahan komunikasi dan menemukan fokus baru dari proses komunikasi.

Teori yang berasal dari filosofi Cina dapat ditempatkan sebagai yang paling kritis melihat eksistensi manusia sebagai keseluruhan dan menolak untuk membuat garis yang tegas antara teori dan praktik. Bagaimana konteks mempengaruhi komunikasi dan bagaimana seseorang bisa menemukan dan mengidentifikasi bagamana konteks tersebut terjawab dalam filosofi Cina.

Pada akhirnya, teori ini menyediakan sebuah metode komunikasi. bagaimana filosofi harmoni Cina diterapkan dengan berbagai taktik untuk mencapai pemahaman bersama dalam komunikasi.
Di sisi lain, mispersepsi yang biasa dalam mempelajari perilaku komunikasi Cina adalah kesalahan perlakuan terhadap "harmoni", menjadi tujuan akhir dari komunikasi cina, dan merupakan representasi nyata dari cara berinteraksi orang cina. Chen (2004) menunjukkan permasalahan ini dengan pernyataan bahwa ada dua wajah komunikasi Cina dilihat dari perspektif harmoni. Argumen ini berdasarkan pada cara berpikir filosofis orang cina dan pengamatan dalam interaksi actual keseharian orang cina. Filosofi orang Cina menyatakan bahwa sebagaimana proses perubahan dan transformasi, komunikasi manusia mencerminkan keberadaan dua kekuatan yang berbeda tapi saling melengkapi, contohnya yin dan yang. Dalam komunikasi, yin mewakili atribut kehalusan dan kerendahan, sementara yang menggambarkan kekerasan dan dominasi. Mereka membentuk dua sisi masa uang dan keduanya terlihat secara simultan dalam proses komunikasi dengan derajat kekuatan yang berbeda yang mengarahkan pada situasi interaksi yang simetris ataupun tidak simetris.

Selanjutnya menurut Chen, wajah pertama dari komunikasi Cina yang ditempelkan pada konsep harmoni telah mengakar dalam pikiran dan hati orang cina sejak berabad-abad yang lalu. Dalam hal ini, semua tindakan ditujukan untuk mencapai harmoni, dan standar serta panduan moral 
berbed diterapkan untuk mencari perilaku yang cocok agar keharmonian terpelihara dan tercapai.

Wajah kedua dari komunikasi Cina muncul dari pertanyaan: apa yang akan terjadi jika harmoni tidak dapat terlaksana dalam interaksi? Tidak selamanya orang Cina dapat menunjukkan keqi (kesopanan) bila berada dalam kondisi oposisi atau berlawanan. Dalam tahap awal interaksi, memang orang cina selalu memperlihatkan sikap yang mengagumkan yang terlihat dari rasa hormat, timbal balik yang positif, dan rendah hati untuk membangun iklim komunikasi yang harmoni (Xiao dalam Chen). Namun jika aturan "rendah hati dan menghormati orang lain" ini tidak berbalas, orang cina tidak segan memperlihatkan perilaku agresif untuk "menyelamatkan" wajah mereka. Dan ini tentu saja dapat mengarah pada situasi konflik.

Situasi-situasi konflik tentu kerap dihadapi dalam kehidupan sehari-hari terutama ketika orang berkompetisi untuk mendapatkan sumber daya yang langka atau ketika dua pihak memiliki tujuan interaksi yang tidak cocok. Maka bukanlah hal yang aneh jika harmoni kemudian tidak dihiraukan ketika kedua belah pihak berseteru (Hwang dalam Chen). Dalam situasi konflik dimana harmoni tidak dapat dipelihara, orang cina cenderung untuk bertengkar atau bahkan berkelahi demi kepentingan pribadi mereka. Tidak heran jika orang-orang Barat menyatakan bahwa orang Cina memiliki sifat "langsung" dan agresif, atau memperlihatkan emosi secara nyata di depan publik.

Penting bagi kita untuk menyadari dua wajah ini dalam mempelajari inkonsistensi atau ketidaksesuaian komunikasi Cina yang disebabkan oleh penekanan atau penarikan kekuatan yin dan yang. Apa yang ingin diraih dengan menekankan tercapainya yin dan yang ini adalah perubahan dari oposisi kepada kerja sama karena kepercayaan mereka terhadap peran esensial harmoni dalam interaksi manusia. Transformasi dari oposisi ke kerja sama ini adalah proses yang sulit, namun melalui proses penyangkalan, individu dapat menyemai potensi resolusi ketika berada pada kondisi oposisi dalam rangka mengembangkan kapasitas adaptasi perilaku yang tepat dalam menghadapi kontradiksi. Singkatnya, orang Cina percaya perilaku komunikasi apapun dalam kondisi oposisi, termasuk penolakan, penyangkalan atau bahkan konflik, pada akhirnya akan berujung pada muara yang sama yakni tercapainya kondisi yang seimbang.

\section{Keterkaitan dengan Teori Lain}

Sebagai sebuah teori yang berasal dari nilai-nilai filosofis Cina, Chinese harmony communication theory berkaitan erat atau berakar dari tiga teori utama yaitu Taoism Communication Theory, Buddhis communication Theory, dan Confusian Communication Theory. Ketiga teori ini, 
dengan penekanan yang berbeda, merupakan teori besar yang mengusung harmoni sebagai nilai inti kesinambungan kehidupan. Taoism menekankan harmoni dengan alam, budhism menekankan harmoni dengan diri sendiri, dan confusian yang menekankan harmoni dengan orang lain.

Selain berkaitan dengan teori-teori tersebut, Chinese harmony communication theory juga berkaitan dengan teori-teori barat, contohnya adalah structural fungtional dan speech act theory.

\section{Confusian Communication Theory}

Konfusianisme adalah pandangan dunia, ideologi politik, etika sosial, tradisi ilmiah, dan cara kehidupan. Sebagai salah satu tradisi pemikiran yang paling menonjol, Konfusianisme menjadi landasan abadi pada sistem sosial, politik, dan sistem nilai di Asia Timur. Konfusius (551-479 SM) melihat alam semesta sebagai suatu keseluruhan organik dan semua modalitas makhluk yang ada di dalamnya saling berhubungan dan diatur oleh sebuah pemersatu kekuatan, Dao (Jalan). Dao dan tao adalah hal yang sama. Istilah tao digunakan lebih tua pada sistem WadeGiles sementara istilah dao dalam sistem pinyin modern.

Saat ini banyak ilmuwan yang sudah menggeser penggunaan kata Tao menjadi Dao dengan alasan fonetik dan pengucapan yang lebih mudah dalam bahasa Mandarin. Dao merupakan harmonisasi organisasi kehidupan yang menjunjung tinggi dan melestarikan tatanan moral.

Dengan mengikuti Dao, manusia dapat memperoleh pengetahuan tentang diri mereka sendiri; mendapatkan wawasan sebagai manusia secara keseluruhan, serta sendiri dan memperoleh kebajikan, kemampuan untuk mencapai keselarasan baik dalam diri sendiri dan dengan orang lain.

Konfusian menetapkan tiga kebajikan utama untuk menentukan hubungan manusia yang tepat: ren (kemanusiaan), yi (kebenaran), dan $l i$ (kesusilaan, ritus, dan upacara). Nilainilai inilah salah satunya yang diambil oleh Guo Ming Chen untuk membangun Chinese harmony communication theory.

Perhatian fundamental Konfusianisme adalah ren, belajar menjadi manusiawi. Manusia ren adalah manusia yang (a) mencintai semua manusia; (b) yang ingin mengembangkan dan memelihara diri sendiri, mengembangkan dan memelihara orang lain; dan (c) tidak lakukan sesuatu pada orang lain apa sebagaimana ia tidak ingin sesuatu itu pula terjadi padanya.

li (kesusilaan, ritus, dan ritual), adalah norma social yang mengatur 
tindakan manusia. $\mathrm{Li}$ mengatur perilaku manusia agar sesuai kesadaran prinsip ren dan perhatian yang tulus bagi orang lain. Dengan mengikuti $l i$ orang dapat mendisiplinkan pikiran dan tindakan mereka sampai mereka mencapai prinsipprinsip yang tepat dapat diberlakukan alam.

Hui-Chin Chang, seorang profesor dari University of Ilionis Chicago (dalam littlejohn, 2009:171), berdasarkan analisisnya terhadap teks klasik "Analects Konfusius", menjelaskan pandangan Konfusius terhadap bahasa dalam interaksi manusia dan hubungan sosial. Konfusius mempertimbangkan tujuan komunikasi sebagai etika, yaitu untuk mematuhi dan mempertahankan tatanan moral masyarakat manusia.

Konfusianisme tidak percaya dan tidak suka pada kata-kata yang penuh hiasan namun tidak jelas substansi dan nilai moralnya. Menurut Konfusius, tindakan lebih berarti dan bermaksa dalam menilai integritas seseorang. Menurut June Ock Yum, profesor antropologi dari Baltimore Hebrew university (dalam LittleJohn, 2009:172), dalam hubungan interpersonal orang Asia lebih penuh perhatian. mereka menyadari posisi mereka dalam jaringan hubungan manusia yang kompleks. Hubungan tersebut dipandang sebagai suatu jalinan yang akan dibina dalam jangka panjang. tidak seperti orang barat yang melihat hubungan bersifat jangka pendek dan sesuai kepentingan. Dalam Chinese harmony communication theory, ini adalah pada konsep quanxi, mientz, dan power.

\section{Taoism Communication Theory}

Falsafah Tao dapat berada pada dua sisi terhadap konfusian, ia merupakan kebalikan sekaligus pelengkap. Pendiri Taoisme, Laozi ( abad ke-6 SM) dan Zhuangzi (abad ke-4 SM), meyakini tao sebagai kekuatan yang dioperasikan untuk menjaga dunia dalam harmoni. Laozi dan Zhuangzi menganjurkan gagasan Wuwei (tindakan tanpa usaha), yang telah menyebabkan Taoisme dikaitkan dengan tema kealamian, spontanitas, keterkaitan, pluralisme, anarkisme, dan pemerintah laissez-faire. Karya-karya utama

Inti ajaran Taoisme adalah "Dao" yang berarti tidak berbentuk, tidak terlihat, tapi merupakan proses kejadian dari semua benda hidup dan segala benda-benda yang ada di alam semesta. Dao yang berwujud dalam bentuk benda hidup dan kebendaan lainnya adalah De. Gabungan Dao dengan De dikenal sebagai Taoisme yang merupakan landasan kealamian. Taoisme bersifat tenang, tidak berbalah, bersifat lembut seperti air, dan bersifat abadi. 
Taoisme menjadi landasan Chinese harmony communication theory karena merupakan ajaran yang memperkenalkan konsep Yin yang. Yin yang saling melengkapi untuk menghasilkan tenaga atau kekuatan. Kekuatan tersebut sebagai sumber dari jutaan benda di dunia. Setiap benda di alam semesta yang berupa benda hidup ataupun benda mati mengandung Yin yang yang saling melengkapi untuk mencapai keseimbangan.

Secara terminologi, Yin dan Yang diterjemahkan.

Pandangan Tao terhadap Komunikasi berbeda dengan pandangan barat. Bila pandangan barat menyukai pembicara yang kuat, asertif, dan defensive, maka Tao lebih menyarankan perilaku komunikator yang sebaliknya. Tao memandang bahwa menjadi lemah lembut dan rendah hati berarti mengosongkan hati, melunakan kehendak, dan mensubordinasi perasaan egois seseorang untuk membuka diri ke dunia luar. Untuk melakukannya pembicara mengesampingkan standar baik dan buruk yang ditetapkan dan bebas dari cengkeraman pengakuan dan arus pikir sosial. Hal ini juga menunjukkan bahwa pembicara bersedia untuk melayani kesejahteraan pendengar dan mengakomodasi sudut pandang alternatif dari orang lain.

\section{Bhuddist Communication Theory}

Bhuddist communication theory merupakan teori yang dibangun berdasarkan pada bagaimana sang Buddha berkomunikasi. Buddha lahir di India pda 563 SM dan meninggal pada usia 85 tahun.

Buddha adalah komunikator yang sangat persuasif. Ia berkhotbah kepada orang-orang dalam idiom dan kosakata yang mudah dimengerti. Dia berbicara dengan memperhatikan aspek psikologis dari lawan bicara dan pendengarnya. Selain itu, Buddha merancang pesan-pesannya dengan cara yang akan menarik orang-orang biasa. Dalam hal model komunikasi, ia menempatkan penerima di pusat komunikasinya model seperti kebanyakan Model Barat. Bukan hanya itu, Buddha mengonseptualisasi pesan-pesannya sesuai dengan konteks. Ia menempatkan penekanan besar pada strategi retoris digunakan oleh komunikator. Sehingga dapat dikatakan bahwa komunikasi merupakan sentral dari pemikiran Buddhist.

Ada lima pengandaian utama terkait dengan tatanan sosial yang ideal yang berkaitan dengan chinese harmony communication theory, yakni: (1) Manusia adalah yang tertinggi, (2) alasan dan pemahaman penuh kasih harus membimbing tindakan manusia bukan dogma buta , (3) manusia harus pragmatis dalam perilaku mereka, (4) segala bentuk kekerasan harus dihilangkan, dan (5) kedamaian dan keharmonian adalah kondisi ideal sebuah masyarakat (Littlejohn, 2009:83-85). 


\section{Teori Struktural Fungsional}

Teori struktural fungsional, yang diperkenalkan oleh Talcott Parsons, merupakan teori ini memfokuskan kajian pada struktur makro yakni pada sistem sosial, yang melalui teori ini Parsons menunjukkan pergeseran dari teori tindakan ke fungsionalisme struktural. Bangunan teori fungsionalisme struktural Parsons banyak terpengaruh oleh pemikiran Durkheim, Weber, Freud dan Pareto.

Teori struktural fungsional Parsons berkonsentrasi pada struktur masyarakat dan antar hubungan berbagai struktur tersebut yang dilihat saling mendukung menuju keseimbangan dinamis. Perhatian dipusatkan pada bagaimana cara keteraturan dipertahankan di antara berbagai elemen masyarakat (Rietzer,

2011:83).

Keseimbangan dinamis ini selaras dengan konsep harmoni yang ada dalam Chinese harmony communication theory.

Pandangannya pada masyarakat sebagai sebuah sistem yang terdiri dari bagian-bagian atau subsistem yang saling tergantung, teori ini menganggap integrasi sosial merupakan fungsi utama dalam sistem sosial. Integrasi sosial ini mengonseptualisasikan masyarakat ideal yang di dalamnya nilai-nilai budaya diinstitusionalisasikan dalam sistem sosial, dan individu (sistem kepribadian) akan menuruti ekspektasi sosial. Maka, kunci menuju integrasi sosial menurut Parsons adalah proses kesalingbersinggungan antara sistem kepribadian, sistem budaya dan sistem sosial, atau dengan kata lain, stabilitas sistem (Ritzer 2011:280-281).

Dalam mengoperasionalkan fungsi sistem sosial yang terkait dengan subsistem, Parsons mengajukan empat skema fungsi penting untuk semua sistem tindakan, yang terkenal dengan sebutan "skema AGIL", yang dipercaya Parsons diperlukan oleh semua sistem sosial. Menurut Parsons, suatu sistem sosial agar tetap bertahan (survive), harus memiliki empat fungsi AGIL ini, yaitu:

\section{A (Adaptation, adaptasi)}

G (Goal Attainment, pencapaian tujuan)

I (Integration, integrasi)

L (Latency, latensi, pemeliharaan pola)

Keempatnya beroperasi dalam relasi input-output dalam pertemuan yang kompleks, dan didudukkan sebagai konsep analitis, bukan deskripsi empiris tentang kehidupan sosial (Ritzer 2011:301-302).

Seperti halnya Chinese harmony communication theory, Teori fungsionalisme struktural ini tampak konservatif, mengagungkan dominasi struktur dan enggan memberi ruang bagi konflik, sehingga seringkali dianggap "anti perubahan sosial". 


\section{Speech Act Theory}

Istilah dan teori mengenai tindak tutur mula-mula diperkenalkan oleh J. L. Austin pada tahun 1956 yang dibukukan oleh J. O. Urmson (1965) dengan judul How to do Things with Words. Teori tersebut baru menjadi terkenal dalam studi linguistik setelah John R. Searle (1969) menerbitkan buku berjudul Speech Act : An Essay in The Philosophy of Language.

Tindak tutur atau "aksi berbicara"/"speech act" adalah pengujaran kalimat untuk menyatakan agar suatu maksud dari pembicara dapat diketahui oleh pendengar. Speech act dapat didefinisikan sebagai an utterance as a functional unit in communication. Tindak tutur adalah salah satu kegiatan fungsional manusia sebagai makhluk berbahasa. Karena sifatnya yang fungsional, setiap manusia selalu berupaya untuk mampu melakukannya dengan sebaikbaiknya, baik melalui pemerolehan (acquisition) maupun

pembelajaran (learning). Pemerolehan

bahasa lazimnya dilakukan secara nonformal, sedangkan pembelajaran dilakukan secara formal

Asumsi speech act theory adalah:

1. Individu membuat suatu wacana yang disebut 'tindakan ucapan' (utterance act) yaitu suatu pengucapan sederhana dari kata-kata pada kalimat yang memiliki tujuan untuk diungkapkan

2. Individu menyatakan sesuatu tentang dunia atau melakukan tindakan pernyataan, membuat pernyataan atau proposisi (propositional act) untuk menegaskan sesuatu melalui ide-ide atau usulan agar audiens meyakini kebenarannya.

3. Individu sedang memenuhi suatu ide atau usulan yang berangkat dari harapan dan masalah melalui tindakan-tindakan konkret.

4. Bagaimana pemenuhan ide memberikan efek terhadap perilaku orang lain.

Menurut Austin, ada 3 syarat agar tuturan performatif dapat terlaksana (felicity conditions), yaitu (1) The persons and circumstances must be appropriate (pelaku dan situasi harus sesuai); (2) The act must be executed completely and corretly by all participants ("tindakan harus dilaksanakan dengan lengkap dan benar oleh semua pelaku) ; (3) The participants must have the appropriate intensions ("pelaku harus mempunyai maksud yang sesuai”)

Semua tuturan pada dasarnya bersifat performatif, yang berarti bahwa dua hal terjadi secara bersamaan ketika orang mengucapkannya. Yang pertama adalah tindak (action), dan kedua berupa ucapan yang dapat digolongkan kepada tiga kategori, yaitu ilokusi, lokusi, dan perlokusi Selanjutnya, konsep performatif dapat 
meliputi bentuk tuturan yang eksplisit dan implisit.

1. Tindak lokusi adalah tindak tutur untuk meyatakan sesuatu. Tindak tutur ini disebut The Act of Saying Something. Konsep lokusi adalah konsep yang berkaitan dengan proposisi kalimat. Kalimat atau tuturan dalam hal ini dipandang sebagai suatu satuan yang terdiri atas dua unsur, yakni subjek atau topik dan predikat atau comment yang relative paling mudah untuk diidentfikasikan karena pengidentifikasiannya cenderung dapat dilakukan tanpa menyertakan konteks tertuturnya tercakup dalam situasi tutur. Contoh: 'Saya lapar', seseorang mengartikan 'Saya' sebagai orang pertama tunggal (si penutur), dan 'lapar' mengacu pada 'perut kosong dan perlu diisi', tanpa bermaksud untuk meminta makanan.

2. Ilokusi adalah tindak melakukan sesuatu. Ilokusi tak lagi membahas mengenai makna suatu ujaran tapi mengacu pada fungsi dan maksud untuk apa ujaran itu dilakukan. Tindak ilokusi memiliki fungsi sebagai tindak tutur untuk menginformasikan sesuatu dan dipergunakan untuk melakukan sesuatu. Perbedaan antara pernyataan atau proposisi dengan tindakan ilokusi adalah suatu proposisi menunjukkan sifat atau hubungan suatu objek, situasi atau peristiwa. "Kue itu enak", "Merokok berbahaya untuk kesehatan", "Kamu cantik" semuanya adalah proposisi. Proposisi dapat dievaluasi dalam hal nilai kebenarannya tetapi anda hampir selalu menginginkan untuk menyampaikan sesuatu yang lebih dari sekedar kebenaran suatu proposisi. Anda ingin melakukan sesuatu yang lain dengan kata-kata anda. Dalam teori bicara, kebenaran tidak dianggap sebagai sesuatu yang sangat penting. Pertanyaan sebenarnya adalah apa yang diinginkan pembicara melalui pernyatannya itu. Karenanya proposisi harus selalu dipandang sebagai bagian dari konteks yang lebih luas yaitu tindakan ilokusioner. Proposisi seperti "Saya bertanya apakah kuenya enak", "Saya mengingatkan anda bahwa merokok berbahaya untuk kesehatan", "Saya mengatakan bahwa kamu cantik". Menurut John Searle, kita mengetahui makna dibalik suatu pesan tertentu karena kita memiliki 'permainan bahasa yang sama' (common language game) yang terdiri atas seperangkat aturan yang membantu kita menetukan kekuatan ilokusioner dari suatu pesan. Searle menegaskan bahwa berbicara dengan suatu bahasa melibatkan suatu bentuk perilaku yang dikontrol oleh aturan (Speaking a language is engaging in a rule governed form of behaviour) (Morissan, 2013 : 151-152). 
3. Tindak perlokusi yaitu hasil atau efek yang ditimbulkan oleh ungkapan itu pada pendengar, sesuai dengan situasi dan kondisi pengucapan kalimat itu. Tindak perlokusi disebut sebagai "The Act of Affecting Someone “.

Dalam kaitannya dengan Chinese harmony communication theory, harmony akan dapat dicapai jika seorang komunikator dapat menyampaikan pernyataan yang dapat menunjukkan intensi atau maksud. Sebaliknya, keharmonian dapat dijaga jika komunikatee dapat melakukan tindak perlokusi yang sesuai.

\section{SIMPULAN}

Dari perspektif komunikasi cina, konsep harmoni adalah yang menaungi hakikat keseluruhan, hubungan yang saling bersambungan, dan cara intuitif dari ekspresi komunikasi. Dengan kata lain, usaha dari komunikasi cina bertujuan untuk mencapai ekuilibrium harmoni, dan proses untuk mencapainya penuh dengan kedinamisan tingkat tinggi.

Orang Cina percaya bahwa semesta berada dalam proses perubahan dan transformasi yang konstan disebabkan oleh interaksi dialektikal dan dialogical antara yin dan yang, dua kekuatan yang berlawanan namun saling melengkapi. Harmoni dianggap sebagai kunci untuk membawa keberlangsungan perputaran transformasi dunia. Dipercayai bahwa harmoni merupakan hasil akhir yang ingin diraih dari komunikasi manusia. Dalam pencapaiannnya, pihak-pihak yang berinteraksi mencoba untuk saling beradaptasi untuk meraih kondisi kesalingbergantungan dan kerja sama.

\section{DAFTAR PUSTAKA}

Chen, Guo Ming, William J. Starosta, 1997, Chinese Conflict Management and Resolution: Overview and Implication", Journal of Intercultural Communication Studies VII: 1 1997-8

Chen, Guo Ming, An Introduction to Key Concepts in Understanding the Chinese: Harmony as the Foundation of Chinese Communication, China Media Research, 7(4), 2011

Chen, Guo-Ming, 2009, Toward an I Ching Model of Communication, China Media Research, 5(3)

Chen, Guo Ming, 2008, Towards Transcultural Understanding: A Harmony Theory of Chinese Communication, China Media Research, 4(4), 2008

Cheng, Yung Ching, 2009, On Harmony As Transformation: Paradigms From The Yijingjournal Of Chinese Philosophy, Supplement To Volume 36 (2009) 1136

Cheng, C.-Y. Toward constructing a dialectics of harmonization: Harmony and conflict in Chinese philosophy. Journal of Chinese Philosophy 33 (2006). 2559. http://dx.doi.org.scihub.org/10.1111/j.15406253.2006.00389.x

Fung Yu-Lan. 1990. Sejarah Ringkas Filsafat Cina: Sejak Confucius sampai Han Fei Tzu. Yogyakarta: Liberty. 
George Ritzer \& Douglas J.Goodman.2011.Teori Sosiologi, Edisi terbaru. Bantul:Kreasi Wacana

Jia, Wenshan, Xing Lu, D Ray Heisey, 2002, Chinese communication theory and research : reflections, new frontiers, and new directions Westport, Conn: Ablex, diakses 10 Desember melalui http://www.worldcat.org/title/chinesecommunication-theory-and-researchreflections-new-frontiers-and-newdirections/oclc/260093614

Morissan. (2013). Teori Komunikasi : Individu Hingga Massa. Jakarta: Kencana Prenada Media Group.

Leung, K., Koch, P. T., and Lu, L. A dualistic model of harmony and its implications for conflict management in Asia. Asia Pacific Journal of Management 19 (2-3) (2002). 201220.http://dx.doi.org.scihub.org/10.1023/A:1016287501806

Littlejohn, Stephen W., Karen A. Foss, 2009, Encyclopedia of Communication Theory: Online Publication Version (September 17, 2009), page 96-97, Sage Publication http://dx.doi.org.scihub.org/10.4135/9781412959384

Miller, Katherine, 2002, Communication Theories: Perspectives, processes, and context, Boston: McGraw-Hill

Takwin, Bagus, 2003, Filsafat Timur: Sebuah Pengantar ke PemikiranPemikiran Timur, Yogyakarta: Jalasutra 